\title{
CORPO \& LUGAR: REPENSANDO EXTENSÕES, CONSIDERANDO DISTENSÕES
}

Candice Didonet (Universidade

Federal da Paraíba)

Thiago de Araújo Costa (Universidade de São Paulo)

RESUMO: A prática extensiva que gera este artigo atualizou vivências do lugar ocupado: o NAC - Núcleo de Arte Contemporânea da Universidade Federal da Paraíba. O Curso de extensão "Corpo \& Lugar" realizado com a abertura da licenciatura em Dança na mesma instituição, provocou ações (per) formativas abordando sentidos de lugar na contemporaneidade sob o viés da pesquisa artística. Enfatizando contextos em João Pessoa com referenciais que transitaram entre dança, artes visuais, performance e urbanismo, experimentos foram propostos para problematizar relações entre corpo(s) e lugar.

ABSTRACT: The extensive practice that generates this article updated experiences of the place occupied: the NAC - Contemporary Art Center of the Federal University of Paraíba. The Extension Course "Body \& Place" held with the opening of the graduation in Dance at the same institution, provoked (per) formative actions addressing the senses of place in contemporary times under the bias of artistic research. Emphasizing contexts in João Pessoa with references that transited between dance, visual arts, performance and urbanism, experiments were proposed to problematize relations between body (s) and place.

Palavras-chave: Corpo. Lugar. Artes contemporâneas. Pesquisa artística.

Keywords: Body. Place. Contemporary arts. Artistic research.

Como tratar a dança enquanto prática ligada à pesquisa artística nos lugares e com os vínculos relacionais que a compõe? A abertura do curso de licenciatura 
em Dança na Universidade Federal da Paraíba em outubro de 2013, sinalizou a necessidade de práticas extensivas abertas à comunidade da cidade de João Pessoa. No entanto, em um primeiro momento, não foi possível identificar quem integrava a comunidade interessada em participar e, para que este mapeamento acontecesse foi usada a estratégia de diálogo da dança com outros campos de conhecimento. Este diálogo causou experiências artísticas ampliadas que buscaram distender ações entre diferentes áreas no campo das artes contemporâneas.

A fim de questionar relações entre corpos, lugares e sentidos gerados a partir de experiências artísticas e (per) formativas no contexto das artes contemporâneas, o conteúdo programático do curso de extensão "Corpo \& Lugar" visou referenciar/ manusear ideias e relações entre dança e site-specific (sítio específico) com reflexões acerca de entendimentos de corpo, espaço, performatividade, cidade e lugar nas artes contemporâneas. O caráter prático do curso se colocou de forma experimental valorizando proposições de mapeamentos de trajetos no entorno do NAC - Núcleo de Arte Contemporânea da Paraíba, no centro da cidade de João Pessoa. Os procedimentos experimentais visaram proporcionar caminhadas enquanto práticas artísticas relacionando mobilidades e deslocamentos enquanto experiências de lugar, carinhosamente apelidados de "lugariz (ações)" no entendimento da caminhada enquanto prática estética, como sugerida por Careri (2013).

Um dos primeiros desafios apontados na realização do curso foi a dificuldade em mapear quem eram os artistas locais que experimentam propostas e relações entre dança, performance arte e site specific. Para isso foi sugerida a ocupação de um espaço que contemplasse as artes contemporâneas em geral e que estimulasse a vinda da comunidade interessada em participar de um curso de extensão.

O NAC - Núcleo de Arte Contemporânea da Paraíba foi então o lugar provocador do curso, pela sua importância no panorama das artes contemporâneas do Brasil, por colocar-se diferenciadamente para a realização dos acontecimentos que compuseram a prática extensiva e pela sua localização no centro da cidade, distante do campus principal da universidade. Assim, surgiu a seguinte questão: 
se o sentido do "lugar NAC" resulta da partilha cultural local que se relaciona com conhecimentos disponíveis para comunidades de pessoas interessadas, como se propõe um sentido de lugar para os recém-chegados, desintegrados de uma memória anterior?

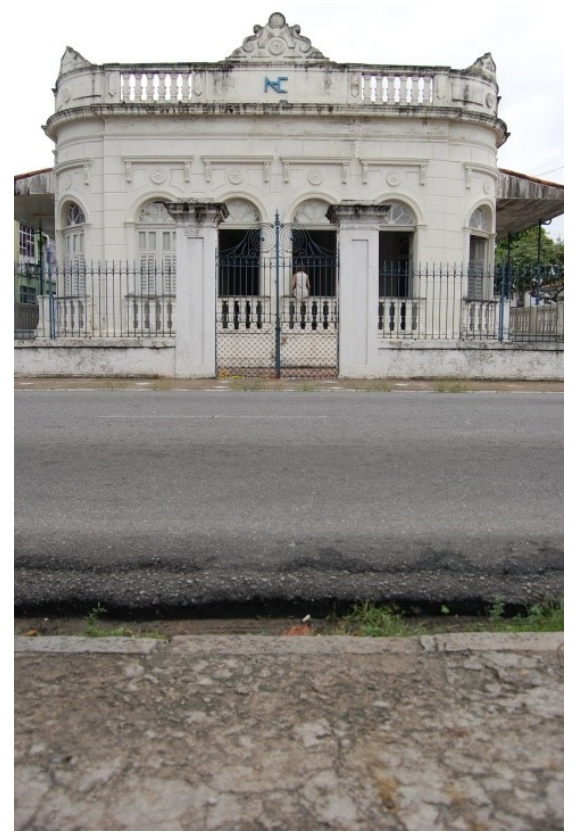

Fachada do NAC. Fotografia Ramon Benício. Agosto de 2013.

A experiência do NAC no campo da extensão universitária atravessa muitas dificuldades e um processo de abandono que demonstra a urgência de continuidade e de memória. Este espaço foi implantado a partir de 1978 em plena época de repressão política através de um acordo entre a Universidade Federal da Paraíba e a Fundação Nacional de Arte - FUNARTE através da proposição de Francisco Pereira Júnior, Paulo Sérgio Duarte, Antonio Dias e Raul Córdula.

Situado na Rua das Trincheiras, no centro da cidade de João Pessoa este antigo casarão carece de manutenção e seus espaços e acervos enfrentam diversos problemas nas últimas três décadas. Na falta de recursos e entendimento de sua habitação por parte da universidade, o processo de falta de memória e reconhecimento só parece aumentar, gerando um processo de agonização deste espaço já considerado especial para as artes visuais no Brasil. Dentro da Coleção "Fala de Artista" concebida pela professora, artista visual e pesquisadora Glória Ferreira (RJ) em parceria com a FUNARTE, é possível acompanhar um pedaço da importante trajetória deste lugar. Neste livro 
organizado pelo artista paraibano Dyógenes Gomes (2004) estão textos e entrevistas de artistas reconhecidos em territórios amplos e que passaram pelo NAC como: Antônio Dias, Arthur Barrio, Rubens Gerchman e Cildo Meireles.

A institucionalização e o tombamento do casarão dificultam alguns aspectos da memória e facilitam outros. Sabe-se que o tombamento sinaliza ambivalências e é um assunto complexo e de nuanças que envolvem a manutenção física do lugar. Entre 2013-2014, com problemas em sua gestão, o espaço ficou sem atividades cotidianas que aproveitassem suas várias salas internas. As exposições que foram realizadas não passaram por um processo de curadoria ou seleção, o que as tornaram cada vez mais descoladas do lugar, que passa ser apenas o recipiente para amostragens criando dinâmicas de passagem, e não, de vínculos. Este tipo de relação reforça o espaço com a ideologia que considera um lugar de exposição neutro, representado pela metáfora do cubo branco como sugerida por Odoherty (2002). Porém, a urgência de ressignificação desta ideologia envolve cada vez mais os vínculos relacionais e propostas que articulem atividades e outras práticas e ações em seu entorno.

Foi neste contexto que o curso de extensão "Corpo \& Lugar" se colocou, buscando atualizar para inventar novas possibilidades de se relacionar com o "lugar NAC" e os espaços da cidade em seu entorno. O curso, iniciado em outubro de 2013, completou seu primeiro módulo de vinte horas com vinte pessoas inscritas, tendo um público bastante variado, estudantes universitários vindo de diversas áreas, artistas e interessados em artes. Porém, das vinte pessoas inscritas apenas dez compareceram e cinco frequentaram as aulas com assiduidade. Isto tudo acentuado pela dificuldade de chegada ao espaço via transporte público, intensificada pelo seu horário de funcionamento: somente durante o dia. Este horário impede propostas de extensão em rotas alternativas que ampliem a participação da comunidade geral e estudantes com rotina de trabalho diurna.

\section{Repensando extensões}


Tendo como principal objetivo estimular a pesquisa e conhecimento artístico partindo da dança difundida no trabalho das artes contemporâneas para a população da cidade de João Pessoa, o curso buscou desenvolver pensamentos críticos ressaltando a importância da manutenção da memória que promova diálogos entre NAC, estudantes da UFPB, a comunidade em geral, artistas e estudantes da dança, do teatro, das artes visuais e do urbanismo.

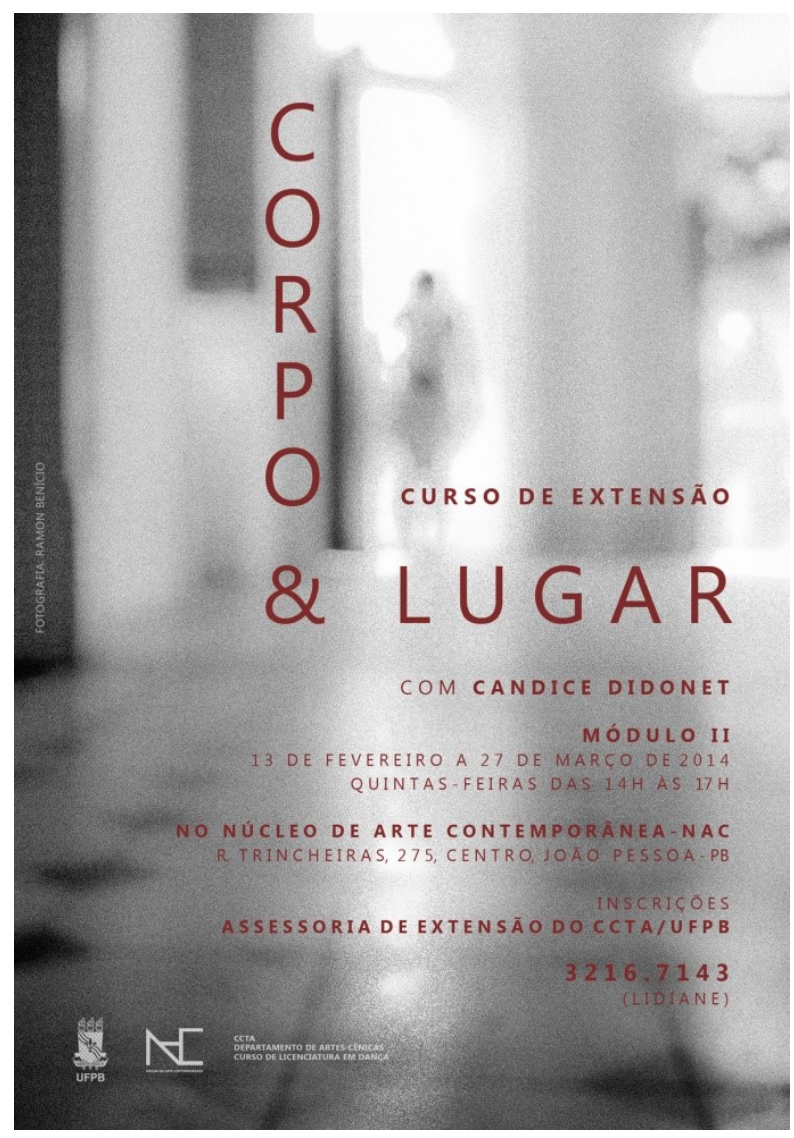

Chamada para o Módulo II do Curso. Janeiro, 2014.

No que tangenciou a relação do NAC com a abertura da licenciatura em Dança da UFPB, o curso de extensão demonstrou a capacidade de potencializar questões referentes à problemática entre corpo (s) e lugar (es). Por estar situado no departamento de Artes Cênicas, o curso de Dança carece agregar valores ligados a ideias de cena e aula que não se descolem dos lugares de pesquisas e acontecimentos. E para além da ideia da espetacularização que separa lugares, espectadores, experiências artísticas, práticas de estudo e artistas.

Deste modo, foi imprescindível propor exercícios que proporcionassem autonomia e experimentação dos conteúdos abordados em aula a fim de testar 
e tentar agregar ideias (per) formativas que atuaram como possibilitadoras de conhecimento reescrevendo vínculos com a cidade.

Cumpre-se assim o perigo maior do experimental: nesses locais áridos ou desérticos da contemporaneidade, ele chega com encantos que a incompreensão trata de tornar ainda mais encantatórios, especialmente se quem o traz é gente da terra com amplo sucesso fora dela. E de uma ação universitária, como a que define o projeto do Núcleo de Arte Contemporânea da Universidade Federal da Paraíba, o que melhor se pode esperar hoje em dia é a capacidade de gerar novos sistemas, não a de meramente absorver e avalizar os já existentes. Abrir espaços e preenchê-los com coisas vivas é bom. Mas vital, porém, e estabelecer crescentes canais de comunicação através deles. Não é só privilegiar a amostragem, que costuma servir mais ao próprio artista, e sim intentar o contágio, que há de atrair e envolver o sempre esquecido público (espectador). $\mathrm{E}$ aqui, sobretudo o público que circula da órbita da universidade (PONTUAL, 2004, p.49).

Redefinir a relação da arte com a universidade torna-se papel ativo na formação de artistas e espectadores na construção de pensamentos críticos em relação aos contextos em que pesquisas artísticas acontecem. A arte revela relações de lugares vivenciáveis em sentidos espaciais/temporais, pois seus contextos geográficos não cessam de alterar modos de experiências corporais que se estabelecem com a cidade através das mobilidades que a permitem experienciála.

Para entender os lugares como espaços físicos enquanto catalisadores de modos de ações e posicionamentos interessa compreender a ideia de lugar a partir de perspectivas vivenciais que são permeadas pelo espaço físico no sentido inscrito e simbolizado abordando espacialidades emblemáticas da vida contemporânea, como as passagens e os fluxos. Os lugares funcionam como pontos de referências dinâmicas possíveis de articular ações locais e globais, públicas e privadas. A importância de práticas extensionistas no âmbito do nascimento de um curso de licenciatura em Dança se deu na problematização da relação institucionalizada que pode dificultar o acesso ao conhecimento, bloqueando a comunicação entre diferentes segmentos nos espaços que ligam a sociedade com a universidade. Dessa forma o Urbanismo nos ajuda a observar a emergência de: 
...Espaços que problematizam a conflituosa geografia contemporânea entre 0 público e 0 privado dissolvem temporariamente os seus limites, denunciando a precariedade das fronteiras e a volatilidade política das barreiras (CANÇADO, 2008, p.10).

Espaços abordados a partir de experiências mobilizadoras para a prática da pesquisa artística na sua dimensão experimentativa conectam as artes contemporâneas em terrenos de observação que se situam nas vivências possíveis dos lugares em que acontecem. Estas vivências possibilitam fluxos corporais da cidade na fruição de seus ritmos com os espaços/tempos que engendram.

\section{Articulando trânsitos com o Urbanismo}

O curso de extensão "Corpo \& Lugar" coligou-se efetivamente ao campo urbanístico, tecendo uma parceria para a realização do workshop "As artes de constranger o ritmo das cidades" proposto pelos autores deste artigo. Realizado em dezembro de 2013 durante dois dias, esteve dentro da programação do Seminário Internacional_Urbicentros\#4, organizado pelas Faculdades de Arquitetura e Urbanismo da UFPB, UFBA e UFRN.

Inserindo-se na problemática corpo\&lugar, corpo/lugar, o workshop visou agregar práticas performativas com experiências de ociosidade e desaceleração na cidade contemporânea de João Pessoa. Foi apresentado um mapa de trabalhos artísticos que constrangem o ritmo de diferentes cidades do mundo e contribuem para potencializar o corpo na ocupação do espaço público. Uma das referências usadas neste workshop foi o artista Francis Alÿs, belga radicado no México. Em uma de suas obras emblemáticas chamada "Paradox of Práxis" (1997) ele arrasta um cubo de gelo pela Cidade do México até derreter, determinando trajetórias e leituras incomuns com o espaço urbano.

O workshop teve como objetivo realizar experimentações de práticas urbanas que buscaram atualizar cadências e compassos do centro histórico da cidade de João Pessoa. Os participantes pesquisaram e performaram situações que permitiram o engajamento da corporeidade e as tensões entre velocidade e lentidão no transcurso urbano. 
A atividade inseriu no programa do curso de extensão outras possibilidades de alargamento da compreensão dos contextos que situam o NAC enquanto lugar praticado. Por ser um evento promovido pelo campo de arquitetura e urbanismo, o diálogo se estabeleceu de modo experimental e ativo buscando no contexto da pesquisa artística conexões entre as dificuldades existentes acerca da inserção da ideia de lugar enquanto argumento para criação de vínculos. Por meio do workshop a presença dos artistas propositores e dos artistas e participantes de fora do curso emergiu, sobretudo, a seguinte reflexão:

\begin{abstract}
O artista que se propõe ou é convidado a trabalhar com lugares deve começar, exactamente por se interrogar sobre as configurações do conceito de Lugar no mundo actual. Tarefa complexa que entra no domínio das problemáticas da relação local/global analisada pelas diversas dinâmicas das ciências sociais e humanas. $O$ artista deverá estar consciente do facto que a definição operativa do lugar se tem vindo a transformar ao longo das últimas décadas, implicando relações de posturas em relação a sua abordagem. Delas não se pode alhear, sobretudo se tiver em conta que o papel da arte pode ter ao trabalhar com os lugares enquanto catalisadores sobre o modo como nos posicionamos, estamos e agimos com o ambiente e nas relações com os outros (TRAQUINO, 2010, p.8).
\end{abstract}

A fim de problematizar as relações entre corpos e lugares, incitou-se a reflexão conceitual acerca da ideia de lugar e sua composição pelas artes contemporâneas. Os lugares podem ser determinados pelas condições de suas organizações espaciais/temporais. Seus espaços físicos estabelecem compreensões acerca de vivências que possibilitam modos de relação entre a pesquisa artística e a cidade habitada criando contextos para diferentes experiências cotidianas. Estes contextos que a cidade, ou, as cidades dentro da cidade proporcionam suscitam a seguinte questão: como a partir da relação entre corpos e lugares as práticas artísticas posicionam recepções e fruições de trabalhos e pesquisas na arte contemporânea?

Torna-se necessário dialogar com o pensamento do autor Jacques Rancière (2010) que propõe ideias acerca do espectador emancipado. Este tipo de espectador é abordado não somente em relação ao seu lugar territorial (plateia), mas com a capacidade de engendrar experiências críticas e reflexivas na percepção e vivência artística que vincula o lugar ao seu cotidiano. Este pensamento é válido no sentido em que as leituras que geram ações reflexivas 
em relação ao lugar do espectador no campo de conhecimento das artes contemporâneas são caracterizadas por muitas tentativas de tornar os espectadores ativos. Propõe-se então neste texto, pensar o lugar a partir de espectadores emancipados que suscitam reflexivamente organizações de espaços/tempos em experiências artísticas (per) formativas.

No contexto das artes cênicas e mais especificamente na dança, o lugar de elaboração da pesquisa artística pode ser separado pela existência de espectadores questionando a organização dos espaços/tempos que emergem a partir da experiência. Os lugares estabelecem vínculos entre o que se assiste e a experiência artística que se experiencia e vive, diferenciando-se da abordagem passiva dos espaços/tempos que articulam em geral. O lugar abordado a partir das características relacionais sociais além das físicas, geográficas e arquitetônicas, situa contextos pela necessidade de atividades extensivas de um modo geral, atividades que relacionem possibilidades de acontecimento artístico em diferentes vínculos tensionando a(s) cidade(s) habitada(s).

Segundo a autora Marta Traquino em seu livro "A construção do lugar pela Arte Contemporânea" (2010), alguns movimentos artísticos advindos da década de sessenta questionaram a relação entre obra de arte, plateia, cidade e lugar. São citados alguns movimentos que trabalham com a ideia de site-specific (sítio específico) e land art (paisagem arte) a partir das artes visuais, mas com a tendência de dialogar com a performance arte, o urbanismo e a dança, principalmente, no que tange o modo de exposição da obra artística e as experiências sentidas pelos espectadores em termos de fruição e vivências corporais.

A land art utilizou-se dos recursos da paisagem para questionar o ambiente das galerias de arte e o posicionamento corporal dos espectadores. A contemplação foi substituída como tentativa de engajar o deslocamento dos espectadores em termos de percepção geográfica. Segundo Tufnell (2016), os artistas de land art pensavam em paisagens ambulantes como campo para a criação artística utilizando-se de recursos disponíveis nos próprios lugares de ação. Marcados pela efemeridade, os espectadores passaram a questionar seu lugar enquanto plateia pelo fato de precisarem ir viver a obra. Este "ir e vir" gerou deslocamentos 
que se tornaram experiências diminuidoras do distanciamento entre corpos e lugares.

Assim, e pelo tensionamento dos lugares de percepção de plateia, a land art apresenta organizações de espaços/tempos vivenciados com e como deslocamentos. Para ilustrar melhor esta ideia: algumas obras necessitam serem percorridas e caminhadas, pois tem tamanho tão grande que o espectador pode nela entrar, o que causa o desaparecimento da ideia de um espectador, modificando a noção de espectador para de um agente.

Já o movimento site-specific, bastante discutido na contemporaneidade, prioriza especificidades locais de um lugar problematizando a relação entre o que será realizado artisticamente e o acontecimento desta ação. Muitas vezes, a noção de site-specific é contraditória. Primeiro, por ser um termo usado sem tradução para o português, e segundo por estar sendo observada mais como metodologia de trabalho do que uma noção, propriamente dita. Também por ser observada em diversos segmentos das artes contemporâneas em campos ampliados de ações. Podem-se citar como referência, danças que problematizam politicamente/poeticamente/performativamente lugares de ação articulados aos aspectos espaciais/temporais que engendram.

Uma das referências que partem da dança para ilustrar a questão do site-specific é o trabalho da artista brasileira Cinthia Marcelle, chamado "Confronto" (2005). Neste vídeo os dançarinos são acrobatas que ocupam simultaneamente uma faixa de pedestre provocando um ruído entre carros afoitos em cruzar um farol. Os acrobatas aos poucos tomam a rua entram e saem dois a dois no circuito, até formarem uma barreira frente ao sinal verde. O poder do fogo e a habilidade dos acrobatas desafiam a buzina estridente dos motoristas questiona espaços da cidade, lugares de passagem, corpos em confronto.

Neste sentido, em danças, corpos e lugares, bem como em suas relações artísticas e (per) formativas, pode-se questionar o estabelecimento de um lugar de plateia repensado em termos de experiência reconfigurando ideias de cena e espectador. Articular o lugar da plateia ativamente nas experiências de formação artística em vivências espaciais/temporais conecta diretamente a percepção e o 
sentido de "lugar". Os modos de ação artística geram a percepção de espaços móveis e flexíveis em relações efêmeras ou passageiras com o processo de recepção dos espectadores. Sendo assim, a recepção dos espectadores deixa de ser determinada somente enquanto espaço físico e passa a ser trabalhada e engajada em campos de ações e vivências perceptivas e sensórias.

Portanto, torna-se necessário observar os deslocamentos de experiências nas artes contemporâneas enquanto questionadoras da compreensão dos seus lugares de acontecimento em processos (per) formativos. As organizações de espaços/tempos podem ser parâmetros que questionam lugares fixos de ação e, os modos de suas configurações emancipam o lugar da plateia no acontecimento de diferentes experiências artísticas.

$\mathrm{Na}$ percepção e ideia de acontecimento do lugar, Zumthor em seu livro "Performance, recepção e leitura" (2007) destaca como as organizações de espaços/tempos propostas pelas artes articulam leituras em seus movimentos de recepção. Muitas vezes é pelo fato de estranhar ou desconhecer lugares, que muitas obras e experiências artísticas se articulam e geram relações. Deste modo, o estranhamento passa a ser considerado parâmetro compositivo de percepção às articulações artísticas que levam em consideração lugares tendenciosos a distender ações ampliando campos e possibilidades de acontecimento das artes.

\section{Considerando distensões}

A partir de referências misturadas, este artigo partiu de uma prática extensiva proposta para pensar o lugar como possibilitador de questionamentos em organizações espaciais/temporais nas artes contemporâneas. No relato do curso de extensão oferecido pela licenciatura em Dança da UFPB, as atividades foram abordadas como processos, e por isto tornou-se impossível prever relações dos lugares que se estabeleceram a partir de experiências. Tornou-se necessário perceber o engajamento corporal que fez o "lugar NAC" vivo, em tentativas de estabelecer vivências como modos organizativos na cidade de João Pessoa e nas situações dos experimentos gerados em aula. 
A ideia de lugar tornou-se articuladora de experimentos que tangenciaram práticas (per) formativas. No que tocou experiências na realidade vivida, os modos de organização dos espaços/tempos propostos foram visibilizados como articuladores de diferentes vivências pelos participantes envolvidos. Mais do que definir modos organizativos ou fixar lugares, buscou-se visibilizar como ambos se articulam, tanto nas experiências artísticas de formação, quanto nas artes contemporâneas. Deste modo, destacou-se a urgência da transdisciplinaridade, de transitar com outras áreas de conhecimento, bem como, da indisciplinaridade, de borrar fronteiras de linguagem entre a dança com o urbanismo e a performance arte.

Observou-se a importância de referenciar alternativas de entendimento para os assuntos de interesse questionando ideias de lugar e organizações de espaços/tempos hegemônicas e unificadas. Buscando não delimitar condições e sentidos de "lugar", partiu-se da observação e compreensão de experiências que distenderam a capacidade de dialogar suas organizações perceptivas. Um lugar é o que torna vivo o compartilhamento de espaços/tempos comuns que experiências artísticas engendram, e por isso, sua emancipação é tratada como vivência além do território arquitetônico que abriga provisórios diálogos entre corpos e lugares.

Estas são considerações transitórias deste texto que teve como foco principal a reflexão sobre as relações com o lugar como compartilhamento de espaços comuns em que experiências (per) formativas e artísticas engendraram, colocando estudantes, artistas, espectadores, e comunidade em geral em diálogo a fim de ressignificar vivências da cidade que habitam.

O artigo não apresenta necessariamente resultados, mas reflexões geradas a partir de um breve início da prática de extensiva "Corpo \& Lugar" aqui circunstanciada que buscou distender questões articulando proposições em fluxos de vivências e pesquisa.

\section{Referências}

BRYAN, Odoherty. No interior do Cubo Branco - A ideologia do Espaço da Arte. São Paulo: Martins Fontes, 2002. 
CANÇADO, WELINGTON. Espaços colaterais. In: CAMPOS, A.; CANÇADO, W; MARQUEZ, R.; TEIXEIRA, C. M. (Orgs.) Espaços Colaterais. Belo Horizonte: Instituto Cidades Criativas, 2008.

CARERI, Francesco. Walkscapes: o caminhar como prática estética. São Paulo: Editora G. Gili, 2013.

PONTUAL, Roberto. Um Núcleo fora do Núcleo (ou como ativar, longe do eixo). In: GOMES, Dyógenes C. (Org.). Núcleo de Arte Contemporânea da Paraíba - NAC. Rio de Janeiro: FUNARTE, 2004.

RANCIÈRE, Jacques. O espectador emancipado. Lisboa: Orfeu Negro, 2010.

TRAQUINO, Marta. A Construção do Lugar pela Arte Contemporânea. Portugal: Edições Húmus, 2010.

TUFNELL, Ben. LAND ART. Tate Publishing: Londres, 2006.

ZUMTHOR, Paul. Performance, Recepção e Leitura. Cosac e Naify: 2007.

Sítios e canais virtuais visitados:

Cinthia Marcelle. https://vimeo.com/2115626. Acesso em 10 de março de 2018.

Francis Alÿs. http://francisalys.com/sometimes-making-something-leads-tonothingl. Acesso em 10 de março de 2018.

\#Urbicentros4. Programação disponível em: http://www.ppgau.ufba.br/urbicentros/2013/wpcontent/uploads/2013/07/WORKSHOPS-URBICENTROS-

PROGRAMA\%C3\%87\%C3\%830.pdf .Acesso em 10 de março de 2018. 